\title{
Clinical presentation and management of anterior capsular contraction
}

\author{
Ramnani $V^{1}$, Gupta $S^{2}$, Ramnani V.K $\mathbf{K}^{3}$ \\ ${ }^{1}$ Dr Vinita Ramnani, Assistant Professor, L. N. Medical College, Bhopal (M.P.), ${ }^{2}$ Dr Saroj Gupta, Professor, Peoples \\ College of Medical Sciences and Research Center Bhopal (M.P.), ${ }^{3}$ Dr Vijay Kumar Ramnani, Professor and Head, \\ Department of Microbiology, L. N. Medical College, Bhopal (MP).
}

Address for Correspondence: Dr Vinita Ramnani, 12 Sunvilla, Kaliyasoat Dam Road, Chunabhatti, Bhopal (M.P.). Email- ramnanivinita@yahoo.co.in

\begin{abstract}
Purpose: Aim of this study is to analyze clinical presentation and predisposing risk factors of anterior capsular contraction following phacoemulsification and to assess challenges encountered in management. Methods: This is retrospective study of anterior capsular contractions of capsulorhexis following phacoemulsification. All patients were analyzed for clinical presentation by detail history and slit lamp examination. YAG laser capsulotomy or surgical excision of phimosis was done and various challenges encountered in management were detailed. Results: Total 20 patients (23 eyes), age between 26 years 72 years,, with 13 male and female 7 were analyzed retrospectively. The predisposing risk factors noted were Uveitis ( 7 patients), myopia (3 patients), pseudo exfoliation ( 2 patients), diabetes (3 patients), trauma (1 patient), both diabetes and uveitis (1 patient), Status post phacovitrectomy (1 patient) and no accompaniments in ( 2 patients). We managed 18 patients (21 eyes) by observation in ( 3 eyes), YAG laser in (7 eyes), simple surgical excisions in ( 8 eyes), excision with vitrector (1 eye), aspiration of milky fluid behind IOL from bag (1 eye) and phimosed dislocated bag removal from anterior chamber and intraocular lens (IOL) exchange with (SF) scleral fixated IOL (1 eye). Conclusions: Anterior capsular contraction is more common with patients with various risk factors and has varied clinical presentations. Simple procedures like YAG and surgical excision will help patients to restore vision.
\end{abstract}

Key words: Anterior capsule opacification, Capsule contraction syndrome, Phimosis, cataract, Intraocular lens and YAG laser.

\section{Introduction}

Continuous curvilinear capsulorhexis (CCC) created during cataract surgery can contract slightly in nonpathologic eyes [1]. The anterior capsular contraction can present in various forms depending upon thickness and associated features like anterior capsular opacification (ACO), anterior capsular phimosis (ACP), anterior capsule contraction syndrome (CCS) and capsular block syndrome (CBS). Many medical conditions can predispose patients for development of significant anterior capsular contraction syndrome. Most commonly encountered conditions are pseudoexfoliation [2], uveitis [3], retinitis pigmentosa [4], myotonic dystrophy [5], diabetes [6], high myopia, advanced age, and trauma. Cataract surgery in patients

Manuscript received $14^{\text {th }}$ August 2016

Reviewed: $27^{\text {th }}$ August 2016

Author Corrected: $14^{\text {th }}$ September 2016

Accepted for Publication $26^{\text {th }}$ September 2016 with operated trabeculectomy or vitrectomy cases with previous subtle zonular damage can leads to progressive zonular changes in some cases and develop CCS. Presence of all such disorders should alert the surgeon to do the procedure of cataract surgery with caution [7, 8]. Either YAG capsulotomy in radial fashion [2] or surgical excision [3] to remove rehexis phimosis and fibrous tissue circumferentially by excision with micro scissors is standard methods for treatment of capsular contraction. In patients with risk factors, by certain preoperative, intraoperative and postoperative considerations the phimosis can be prevented. Similarly the other eye of phimosed patient should be operated with due care with large capsulorhexis and good cortical cleanup to prevent progressive shrinkage of capsular opening [1]. On early sign of capsular contraction, immediate YAG capsulotomy is needed to 
prevent further complication of IOL tilt, decentration or dislocation. Aim of this article is to evaluate the causes and varied clinical presentations of anterior capsular contraction, there risk factors and to asses challenges encountered in management.

\section{Materials and Methods}

This is retrospective study of total 20 patients (23 eyes) of anterior capsular contraction done from January 14 to December 2015. Different variety of cases with significant capsular contraction was included in study and evaluated. Systemic and ocular history including details of previous surgery was noted. Visual acuity and detail slit lamp examination including types of capsular contraction; its varity and position of IOL were recorded. Fundus examination done to see any other associated cause for reduced vision. Anterior segment photos for record and explanation purpose were taken for each patient. Predisposing risk factors and type of capsular contraction were noted. Depending upon thickness, type of capsular contraction and severity of phimosis patients were subjected to either observation or YAG or surgical excision. Four eyes were kept under simple observation because of good visual acuity and less dense phimosis, 2 were other eye of bilateral involvement patient. The procedure for YAG capsulotomy adopted was, after taking informed consent and discussion with patient, the pupil was dilated. The YAG settings were low power settings of 1.25 to $1.75 \mathrm{~mJ}$ to create equally spaced three or four radial cuts, each cut nearly 1.0 to $1.5 \mathrm{~mm}$ long given to capsular fibrosis to enlarge the opening. The great caution is taken in YAG laser to keep the excision round and as central as possible and laser beam should be defocused anteriorly to avoid pitting of lens. $\mathrm{Nd}$ : YAG laser, if done early is enough and usually alleviate the capsular force on IOL and zonules. Post laser steroid and antiglaucoma drops were given for one week. If the visual axis is occluded completely by thickened fibrous tissue and dense phimosis, it needs surgical excision. Simple excision of capsular thickening was done with the help of micro scissors in dilated pupil after peribulbar injection and informed consent. One case presented with bilateral dense phimosis and partially subluxated bag inferiorly with $6 / 9$ vision. This patient was therefore followed up for 6 months with stable appearance. But unfortunately one day patient suddenly presented with markedly reduced vision in (RE) and total dislocation of bag with IOL in anterior chamber. After proper informed consent patient was taken to operation theater under peribulbar block, and whole bag along with capsule and IOL under high density viscoelastics was removed from anterior chamber. After making 2 triangular scleral flaps at 3 and 9 o'clock position, with single point fixation scleral fixated IOL was implanted successfully. The routine postoperative treatment of antibiotic and steroid drops was given and patient gained 6/12 vision following surgery. Other eye (LE) condition of phimosis with inferior subluxation was same with stable vision on followup. In one patient of capsular block syndrome the milky fluid was aspirated from bag through $2 \mathrm{~mm}$ side port temporally by MVR blade under surface anesthesia with good postoperative results.

\section{Results}

Total 20 patients (23 eyes) of anterior capsular contractions were analyzed for causes and different varity of clinical presentation. History of trauma noted in one patient with cricket ball and one patient underwent combined phacoemulsification and vitrectomy for eales disease. Age distribution 26 years 72 years (mean 58 years), male 13 and 7 female, mean time interval from cataract surgery to capsular contraction was three months. The predisposing risk factors were present in 18 patients in our series. Uveitis being commonest risk factor ( 7 patients), followed by diabetes in 4 patients, showing common cause being nondialating pupils in both conditions. The other risk factors noted were high myopia ( 3 patients), pseudo exfoliation ( 2 patients), and both diabetes and uveitis (1 patient).

Bilateral involvement found in 3 patients, out of which bilateral subluxation of bag and IOL noted in 2 patients. Depending upon the density and type of capsular contraction we performed successful YAG radial capsulotomy of anterior capsular fibrosis in 7 eyes. Two patients had posterior capsular opacification required YAG posterior capsulotomy too. Eight eyes presented with very thick dense capsular phimosis required simple surgical excision. In one case of uveitis thick anterior and posterior capsule was cut with the help of vitrector.

Out of 4 eyes presented with CCS one eye with anterior dislocated bag with IOL, needed IOL exchange. One eye with CBS required milky fluid aspiration from bag. The results of YAG and surgical excision are encouraging with good regain of visual acuity. There were no significant complications encountered and no recurrence. 


\begin{tabular}{|c|c|c|c|c|c|c|}
\hline Age & $\begin{array}{c}\text { Sex } \\
(\mathbf{N}=\mathbf{2 0})\end{array}$ & $\begin{array}{c}\text { Associated } \\
\text { Disorder }(\mathrm{N}=\mathbf{2 0})\end{array}$ & $\begin{array}{c}\text { Type Of } \\
\text { Presentation } \\
(\mathbf{N}=23 \text { EYES })\end{array}$ & $\begin{array}{c}\text { Time Of } \\
\text { Presentation }\end{array}$ & $\begin{array}{c}\text { IOL }(\mathbf{N}=23 \\
\text { EYES })\end{array}$ & $\begin{array}{l}\text { Management } \\
\text { (N=23 Eyes) }\end{array}$ \\
\hline $\begin{array}{c}26 \\
\text { years } \\
\text { to } 72 \\
\text { years }\end{array}$ & $\begin{array}{c}\text { Males } \\
=13 \\
\text { Females } \\
=7\end{array}$ & $\begin{array}{c}\text { Uveitis }=7 \\
\text { Myopia = } 3 \\
\text { Diabetes = } 3 \\
\text { Pesudoexfoliation } \\
=2 \\
\text { Postvitrectomy = 1 } \\
\text { Trauma = 1 } \\
\text { Uneventful = 2 } \\
\text { Both Diabetes } \\
\text { \& Uveitis = 1 }\end{array}$ & $\begin{array}{c}\text { Phimosis = } 11 \\
\text { Anterior Capsular } \\
\text { Thickening } \\
\text { \& Contraction } \\
(\text { ACO })=7 \\
\text { Capsular } \\
\text { Contraction } \\
\text { Syndrome } \\
\text { (CCS })=4 \\
\text { Capsular Block } \\
\text { Syndrome } \\
(\mathrm{CBS})=1\end{array}$ & $\begin{array}{l}\text { One month to } \\
\text { six and half } \\
\text { month } \\
\text { ( mean } 3 \\
\text { months) }\end{array}$ & $\begin{array}{l}\begin{array}{l}\text { Foldable Iol } \\
=20\end{array} \\
\text { PAMA IOL } \\
=3\end{array}$ & $\begin{array}{c}\text { Surgery = } 11 \\
\text { Yag } \\
\text { Capsulotomy } \\
=7 \\
\text { Observation } \\
=3 \\
\text { Refused } \\
\text { Treatment } \\
=2\end{array}$ \\
\hline
\end{tabular}

\section{Discussion}

Anterior capsule contraction occurs following phacoemulsification and IOL implantation due to excessive contraction and fibrosis of anterior capsulotomy obstructing the visual axis and can leads to reduced vision. It can also produce late secondary complications in the form of pseudophacodonesis and IOL tilt, decentration, or dislocation [9, 10]. ACO (Anterior Capsular Thickening \& Contraction) occurring approximately three months post-operatively is less common then posterior capsular opacification (PCO) [6]. ACP is one of the most common complications $\mathrm{CCC}[11] \mathrm{CBS}$ is characterized by a collection of milky white fluid in between IOL and the posterior capsule, which causes diminution of vision associated with myopic shift due to forward movement of IOL and a shallow anterior chamber. The combination of ACO with capsulorrhexis phimosis and IOL decentration is called as capsule contraction syndrome [12]. CCS first described by Hansen [11] and the term "capsule contraction syndrome" was coined by Davison [2] in 1993. There are two main mechanisms for anterior capsular contraction, one is shrinkage of the capsulorhexis opening due to actin filaments of residual lens epithelial cells (LECs) and second mechanism is due to proliferations and metaplasia of these residual LECs [13, 14]. There are many risk factors for development of CCS like zonular weakness, lens design and material [15]. Capsular contraction syndrome can occur following implantation with a variety of intraocular lenses (IOLs) including PMMA [13], silicone [16] and more rarely hydrophobic acrylic lenses [14]. Anterior capsular contraction occurs most frequently and is most pronounced in patients with silicone-plate IOLs [12]. Risk of developing CCS is more so with small size of capsulorhexis [17] and in high risk cases endocapsular rings (CTR) [18, 19] helps in prevention to some extent, though there are reports of developing CCS in spite of CTR [20]. Some time due to extensive fibrosis the CCC opening is rarely visible, these patients can have tilting or decentration and buckling (foldable only) of the IOL. Even subluxation of total bag can also occur; all causes leads to further reduced vision. In severe cases the zonular traction may lead to IOL dislocation and retinal detachment. YAG capsulotomy $[2,6,20]$ in radial fashion or surgical excision [3] to remove rehexis phimosis and fibrous tissue circumferentially by excision with micro scissors is standard methods for treatment of capsular contraction. The use of a diathermy is also efficient in cutting the fibrotic anterior capsule by one single incision in 30 seconds and is very easy, independent of the degree of fibrosis. Optic repositioning or IOL removal or replacement is needed in progressive zonular weakness with severe deformity that needs removal and replacement of the IOL; there is high risk of capsular dislocation and vitreous loss with replacement of IOL. The IOL should be placed in the sulcus, rather than in the badly distorted, fibrotic bag and should consider placing scleral sutures otherwise there is risk of the entire bag / lens complex going to the vitreous. Yeh et al, 2002 described use of vitrector to remove fibrotic membrane in CCS [21] As many medical conditions like pseudo exfoliation, uveitis, retinitis pigmentosa, high myopia, myotonic dystrophy, advanced age, diabetes and trauma (including ocular surgery) can predispose patients for development of 
significant anterior capsular contraction syndrome. Presence of such disorders should alert the surgeon to do the procedure of cataract surgery with caution [22] The subtle zonular damage, from previous surgery of trabeculectomy or vitrectomy can subsequently leads to progressive zonular changes following cataract surgery. Therefore due precaution during cataract surgery and careful follow-up is necessary to prevent possible anterior capsule contraction in such cases. High index of suspicion and early YAG treatment in other eye of phimosis patient will help to prevent severe complication of progressive changes like malpositions of intraocular lens.

This includes posterior vaulting of the IOL causing hyperopia and anterior vaulting of the IOL leading to myopia. Some time "Z syndrome" or cortical retention syndrome with one side of the optic is anterior and one side is posterior, causing optic tilting with pseudophakic astigmatism up to $3.00 \mathrm{D}$. Finally it can lead to IOL decentration or dislocation. The IOL usually dislocate to the vitreous cavity [23], however rarely it might dislocate to the anterior chamber as in our case. Case reports are available in various disorders leading to late spontaneous dislocation of bag and IOL especially in pseudoexfoliation [24]. On literature search we found various case reports of CCS in different disorders like myopia, pseudoexfoliation, retinitis pigmentosa and marfans and many other predisposing diseases, but we found only one case series of 8 cases of CCS among 243 eyes due to IOL memory loss and ACO [25]. In our series we found different verities of capsular contractions with varied clinical presentations which are treated by YAG or surgery depending upon thickness of capsule with good postoperative results.

\section{Conclusion}

Anterior capsular contraction of is known complication of capsulorrhexis, which is more common with small size anterior capsule opening and in patients with risk factors like pseudoexfoliation, myopia, diabetes and weak zonules. The main predisposing risk factor recognized in our series was uveitis. The Patients at risk should be recognized and by proper preoperative, intraoperative and postoperative considerations the phimosis can be prevented. If phimosis develops then patient can be managed either by YAG radial anterior capsulotomy or by surgical excision. The results of surgical excision are encouraging with good anatomical $\&$ functional results. High index of suspicion and early treatment in other eye of phimosis patient will help to prevent severe complication in other eye. Hence, the aim of this presentation is to make clinicians aware of this entity especially in high risk patients like uveitis and small pupil, so that these consequences can be well anticipated and by proper care complications of phimosis is obviated.

Funding: Nil, Conflict of interest: None initiated, Permission from IRB: Yes

\section{References}

1. Joo CK, Shin JA, Kim JH. Capsular opening contraction after continuous curvilinear capsulorhexis and intraocular lens implantation. J Cataract Refract Surg. 1996 Jun; 22 (5): 585-90. DOI : 10. 2147 / OPTH. S21791.

2. Davison JA. Capsule contraction syndrome. J Cataract Refract Surg. 1993 Sep;19(5):582-9.

3. Spang KM, Rohrbach JM, Weidle EG. Complete occlusion of the anterior capsular opening after intact capsulorhexis: clinicopathologic correlation. Am J Ophthalmol. 1999 Mar; 27(3):343-5.

4. Hayashi K, Hayashi H, Nakao F, Hayashi F. Reduction in the area of the anterior capsule opening after polymethylmethacrylate, silicone, and soft acrylic intraocular lens implantation. Am J Ophthalmol. 1997 Apr; 123(4):441-7.

5. Newman DK. Severe capsulorhexis contracture after cataract surgery in myotonic dystrophy. J Cataract Refract Surg. 1998 Oct;24(10):1410-2.

6. Hayashi K, Hayashi H, Nakao F, Hayashi F. Posterior capsule opacification after cataract surgery in patients with diabetes mellitus. Am J Ophthalmol. 2002 Jul; 134(1):10-6.

7. Werner L, Pandey SK, Apple DJ, Escobar-Gomez M, McLendon L, Macky TA. Anterior capsule opacification: correlation of pathologic findings with clinical sequelae. Ophthalmology. 2001 Sep; 108 (9): $1675-81$.

8. Kato S, Suzuki T, Hayashi Y, Numaga J, Hattori T, Yuguchi T, Kaiya T, Oshika T. Risk factors for contraction of the anterior capsule opening after cataract surgery. J Cataract Refract Surg. 2002 Jan; 28 (1): 109-12. 
9. Gimbel HV, Neuhann T. Continuous curvilinear capsulorhexis. J Cataract Refract Surg. 1991 Jan; 17 (1):110-1

10. Hanson S, Crandall A, Olson R. Progressive constriction of the anterior capsular opening following intact capsulorhexis. J Cataract Refract Surg. 1993;19: 77-82

11. Masket S. Postoperative complications of capsulorhexis. J Cataract Refract Surg. 1993 Nov; 19 (6) : 721-4.

12. Tsinopoulos I, Symeonidis C, Frangou E, Dimitrakos SA. Capsule contraction syndrome in eight cases of hydrophobic one-piece intraocular lens implantation. Clin Exp Optom. 2008 Sep; 91(5):469-72. doi: 10.1111/j.1444-0938.2007. 00243.x. Epub 2008 Jan 8.

13. Spang KM, Rohrbach JM, Weidle EG. Complete occlusion of the anterior capsular opening after intact capsulorhexis: clinicopathologic correlation. Am J Ophthalmol. 1999 Mar; 127 (3) : 343-5 doi: 10.1016/ s0002-9394 (98) 00323-7.

14. Sciscio A, Liu C. Anterior capsular phimosis following Acrysof lens insertion. $\mathrm{Br} \mathrm{J}$ Ophthalmol. 1999 Aug; 83 (8):989-90.

15. Ursell PG, Spalton DJ, Pande MV, Hollick EJ, Barman S, Boyce J, Tilling K. Relationship between intraocular lens biomaterials and posterior capsule opacification. J Cataract Refract Surg. 1998 Mar; 24 (3): 352-60.

16. Zambarakji HJ, Rauz S, Reynolds A, Joshi N, Simcock PR, Kinnear PE. Capsulorhexis phymosis following uncomplicated phacoemulsification surgery. Eye (Lond). 1997; 11 (Pt 5):635-8.

17. Sugimoto Y, Takayanagi K, Tsuzuki S, Takahashi Y, Akagi Y. Postoperative changes over time insize of anteriorcapsulorrhexis in phacoemulsification/ aspiration. Jpn J Ophthalmol. 1998 Nov-Dec; 42 (6): 495-8.

18. Nishi O. Intercapsular cataract surgery with lens epithelial cell removal. Part II: Effect on prevention of fibrinous reaction. J Cataract Refract Surg. 1989 May; 15 (3):301-3.

19. Sun R, Gimbel HV. In vitro evaluation of the efficacy of the capsular tension ring for managing zonular dialysis in cataract surgery. Ophthalmic Surg Lasers. 1998 Jun;29(6):502-5.

20. Sudhir RR, Rao SK. Capsulorhexis phimosis in retinitis pigmentosa despite capsular tension ring implantation. J Cataract Refract Surg. 2001 Oct; 27 (10):1691-4.

21. Yeh PC, Goins KM, Lai WW. Managing anterior capsule contraction by mechanical widening with vitrector-cut capsulotomy. J Cataract Refract Surg. 2002 Feb; 28(2):217-20.

22. Gallagher SP, Pavilack MA. Risk factors for anterior capsule contraction syndrome with polypropylene or poly (methyl methacrylate) haptics. J Cataract Refract Surg. 1999 Oct; 25(10):1356-61.

23. Gross JG, Kokame GT, Weinberg DV; Dislocated In-The-Bag Intraocular Lens Study Group. In-the-bag intraocular lens dislocation. Am J Ophthalmol. 2004 Apr;137(4):630-5.

24. Jehan FS, Mamalis N, Crandall AS. Spontaneous late dislocation of intraocular lens within the capsular bag in pseudoexfoliation patients. Ophthalmology. 2001 Oct;108(10):1727-31.

25. Tsinopoulos I, Symeonidis C, Frangou E, Dimitrakos SA. Capsule contraction syndrome in eight cases of hydrophobic one-piece intraocular lens implantation. Clin Exp Optom. 2008 Sep; 91(5):469-72. doi: 10. 1111/j. 1444-0938. 2007. 00243 .x. Epub 2008 Jan 8 .

\section{How to cite this article?}

Ramnani V, Gupta S, Ramnani V.K. Clinical presentation and management of anterior capsular contraction. Int J Med Res Rev 2016;4(9):1662-1666.doi:10.17511/ijmrr. 2016.109.25. 